\title{
Game control methods in avoidance of ships collisions
}

Józef Lisowski, Prof.

Gdynia Maritime University

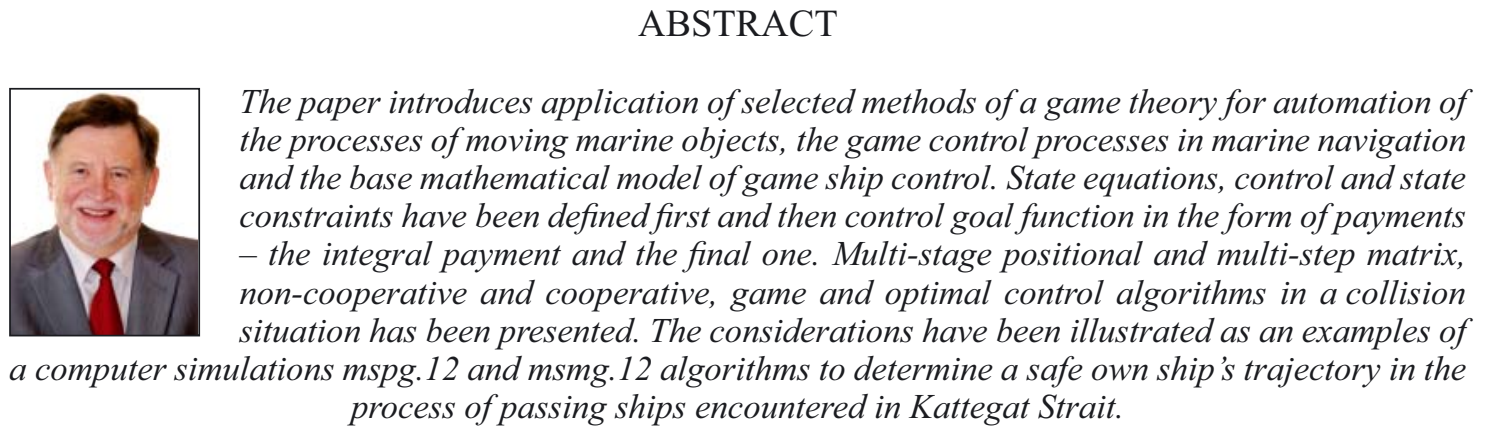

Keywords: marine navigation; safety at sea; safe ship control; optimal control; differential games; positional games; matrix games; computer simulation

\section{INTRODUCTION}

The control of the ship's movement may be treated as a multilevel problem shown in Fig. 1, which results from the division of the entire control system of ship - within the frame of the performance of the cargo carriage by the ship's operator - into clearly determined subsystems which are ascribed appropriate layers of control.

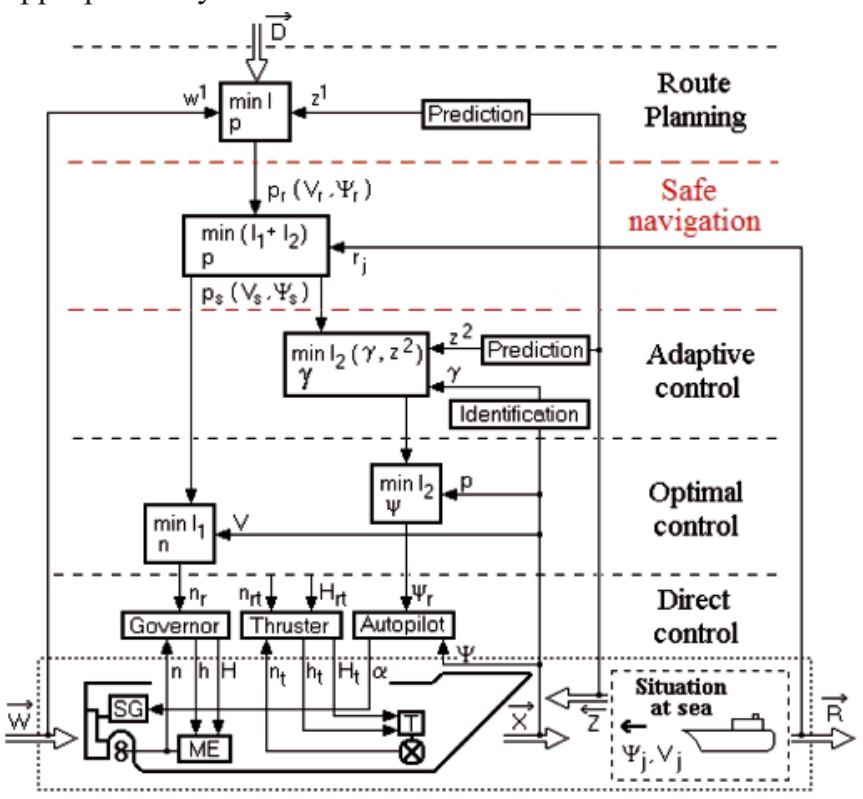

Fig. 1. Multilevel ship movement control system
This is connected both with a large number of dimensions of the control vector and of the status of the process, its random, fuzzy and decision making characteristics - which are affected by strong interference generated by the current, wind and the sea wave motion on the one hand, and a complex nature of the equations describing the ship's dynamics with non-linear and non-stationary characteristics. The determination of the global control of the steering systems has in practice become too costly and ineffective.

The integral part of the entire system is the process of the ship's movement control, which may be described with appropriate differential equations of the kinematics and dynamics of a ship being an object of the control under a variety of the ship's operational conditions such as:

- stabilisation of the course or trajectory,

- adjustment of the ship's speed,

- precise steering at small speeds in port with thrusters or adjustable-pitch propeller,

- stabilisation of the ship's rolling,

- commanding the towing group,

- dynamic positioning of the ship.

The functional draft of the system corresponds to a certain actual arrangement of the equipment. The increasing demands with regard to the safety of navigation are forcing the ship's operators to install the systems of integrated navigation on board their ships. By improving the ship's control these systems increase the safety of navigation of a ship - which is a very expensive object of the value, including the cargo, and the effectiveness of the carriage goods by sea $[1,2]$. 


\section{SAFE SHIP CONTROL IN COLLISION SITUATIONS}

The challenge in research for effective methods to prevent ship collisions has become important with the increasing size, speed and number of ships participating in sea carriage. An obvious contribution in increasing safety of shipping has been firstly the application of radars and then the development of ARPA (Automatic Radar Plotting Aids) anti-collision system $[3,4,5]$.

The ARPA system enables to track automatically at least 20 encountered $\mathrm{j}$ objects as is shown in Fig. 2, determination of their movement parameters (speed $V_{j}$, course $\psi_{\mathrm{j}}$ ) and elements of approach to the own ship $\left(D_{\min }^{j}=\mathrm{DCPA}_{j}\right.$ - Distance of the Closest Point of Approach, $\mathrm{T}_{\min }^{\mathrm{j}}=\mathrm{TCPA}_{\mathrm{j}}$ - Time to the Closest Point of Approach) and also the assessment of the collision risk $r_{j}[6,7,8]$.

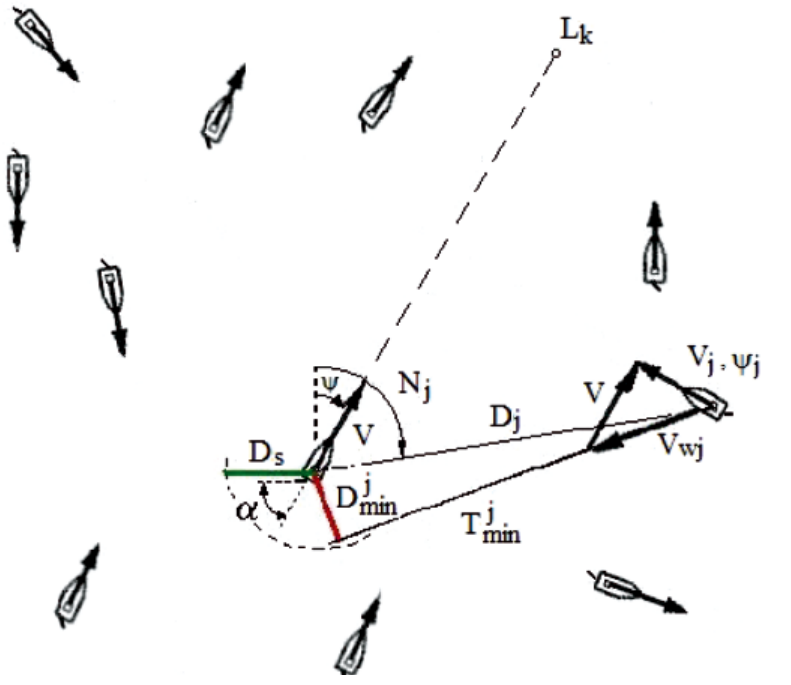

Fig. 2. Navigational situation representing the passing of the own ship with the j-th ship

The risk value (1) is possible to define by referring the current situation of approach, described by parameters $\mathrm{D}_{\min }^{\mathrm{j}}$ and $\mathrm{T}_{\min }^{\mathrm{j}}$, to the assumed evaluation of the situation as safe, determined by a safe distance of approach $\mathrm{D}_{\mathrm{s}}$ and a safe time $T_{s}-$ which are necessary to execute a collision avoiding manoeuvre with consideration of distance $D_{j}$ to $j$-th met ships (Fig. 3) $[9,10,11]$.

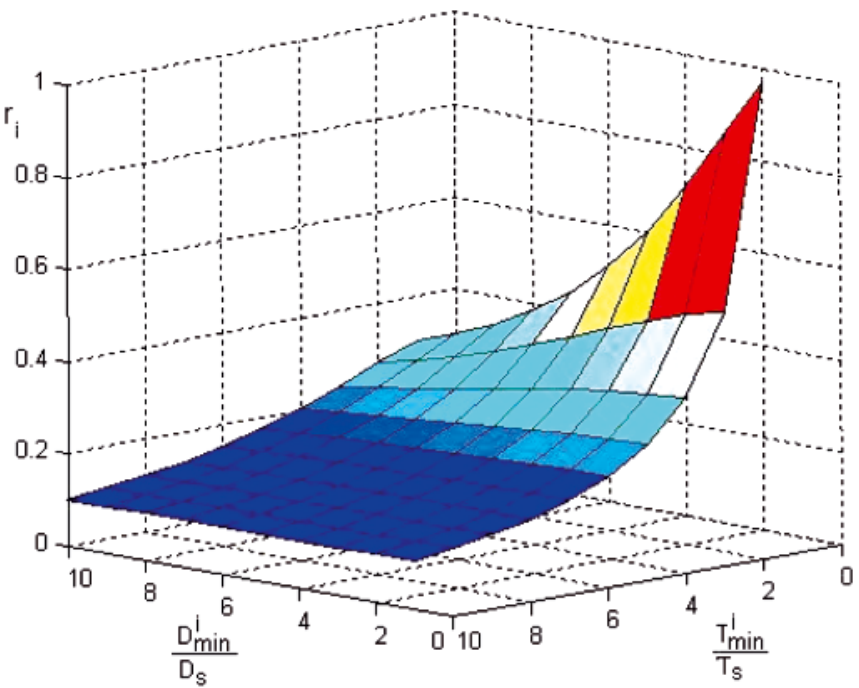

Fig. 3. The ship's collision risk space in a function of relative distance and time of approaching the j-th ships

$$
r_{j}=\left[w_{1}\left(\frac{D_{\text {min }}^{j}}{D_{s}}\right)^{2}+w_{2}\left(\frac{T_{\text {min }}^{j}}{T_{s}}\right)^{2}+\left(\frac{D_{j}}{D_{s}}\right)^{2}\right]^{-\frac{1}{2}}
$$

The weight coefficients $\mathrm{w}_{1}$ and $\mathrm{w}_{2}$ are depended on the state visibility at sea, dynamic length $\mathrm{L}_{d}$ and dynamic beam $B_{d}$ of the ship, kind of water region and in practice are equal:

$$
\begin{gathered}
0 \leq\left[\mathrm{w}_{1}\left(\mathrm{~L}_{\mathrm{d}}, \mathrm{B}_{\mathrm{d}}\right), \mathrm{w}_{2}\left(\mathrm{~L}_{\mathrm{d}}, \mathrm{B}_{\mathrm{d}}\right)\right] \leq 1 \\
\mathrm{~L}_{\mathrm{d}}=1.1\left(1+0.345 \mathrm{~V}^{1.6}\right) \\
\mathrm{B}_{\mathrm{d}}=1.1\left(\mathrm{~B}+0.767 \mathrm{~V}^{0.4}\right)
\end{gathered}
$$

The functional scope of a standard ARPA system ends with the trial manoeuvre by altering the course $\pm \Delta \psi$ or the ship's speed $\pm \Delta$ Vselected by the navigator as is shown in Fig. 4 .

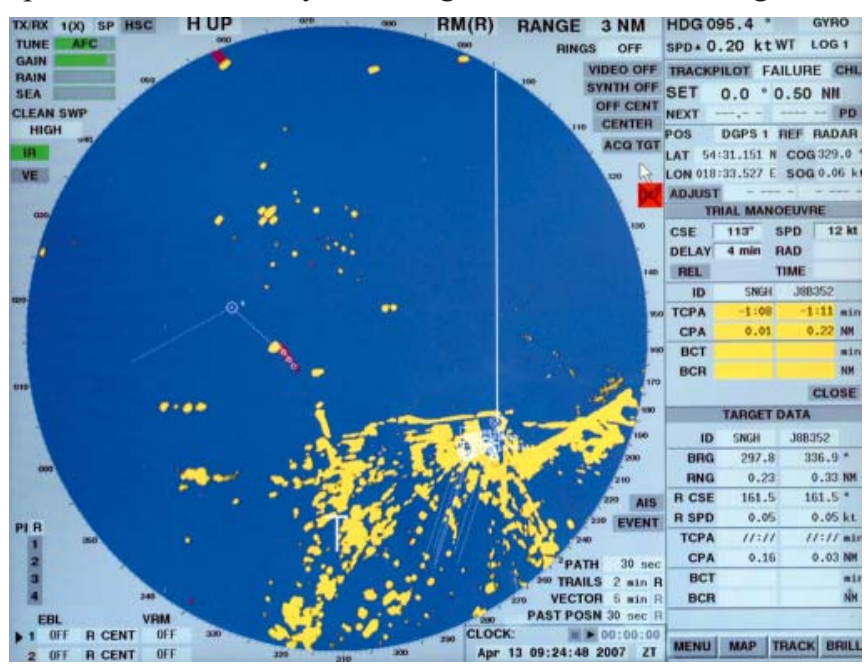

Fig. 4. The screen of SAM Electronics ARPA on the sailing vessel s/ DAR MLODZIEZY

The problem of selecting such a manoeuvre is very difficult as the process of control is very complex since it is dynamic, non-linear, multi-dimensional, non-stationary and game making in its nature.

In practice, methods of selecting a manoeuvre assume a form of appropriate steering algorithms supporting navigator decision in a collision situation. Algorithms are programmed into the memory of a Programmable Logic Controller PLC. This generates an option within the ARPA anti-collision system or a training simulator $[12,13,14]$.

There are various methods for the avoidance of ships collision. The simplest method is determination of the manoeuvre of a change of course or a speed of own ship in relation to the most dangerous ship encountered. A more effective method is to determine safe trajectory of the ship $[15,16,17,18,19,20]$. Most adequate to the real character of control process is determination of a game trajectory of the ship [21, 22, 23].

\section{GAME CONTROL IN MARINE NAVIGATION}

The classical issues of the theory of the decision process in marine navigation include the safe steering of a ship. The problem of non-collision strategies in the steering at sea appeared in the Isaacs' work [24] called "the father of the differential games" and was developed by many authors both within the context of the game theory [25, 26, 27, 28, 29] and also in the steering under uncertainty conditions [30]. 
The definition of the problem of avoiding a collision seems to be quite obvious, however, apart from the issue of the uncertainty of information which may be a result of external factors (weather conditions, sea state), incomplete knowledge about other objects and imprecise nature of the recommendations concerning the right of way contained in International Regulations for Preventing Collision at Sea COLREG [6].

The problem of determining safe strategies is still an urgent issue as a result of an ever increasing traffic of vessels on particular water areas. It is also important due to the increasing requirements as to the safety of shipping and environmental protection, from one side, and to the improving opportunities to use computer supporting the navigator's duties. In order to ensure safe navigation the ships are obliged to observe legal requirements contained in the COLREG Rules.

However, these Rules refer exclusively to two ships under good visibility conditions, in case of restricted visibility the Rules provide only recommendations of general nature and they are unable to consider all necessary conditions of the real process. Therefore the real process of the ships passing exercises occurs under the conditions of indefiniteness and conflict accompanied by an imprecise co-operation among the ships in the light of the legal regulations.

Consequently, it is reasonable for ship operational purposes, to present this process and to develop and examine methods for a safe steering of the ship by applying the rules of the game theory.

A necessity to consider simultaneously the strategies of the encountered objects and the dynamic properties of the ships as the steering objects is a good reason for the application of the differential game model, often called the dynamic game, for the description of the processes [31].

\section{PROCESSES OF GAME SHIP CONTROL}

Assuming that the dynamic movement of the ships in time occurs under the influence of the appropriate sets of steering:

$$
\mathrm{D}_{\min }^{\mathrm{j}}=\min \mathrm{D}_{\mathrm{j}}(\mathrm{t}) \geq \mathrm{D}_{\mathrm{s}}
$$

where:

$\mathrm{S}_{\mathrm{O}}^{(\varepsilon)} \quad-$ a set of the own ship's strategies,

$\mathrm{S}_{\mathrm{j}}^{(\varepsilon)} \quad-$ a set of the $\mathrm{j}$-th ship's strategies,

$\varepsilon=0-$ denotes course and trajectory stabilisation,

$\varepsilon=1 \quad$ - denotes the execution of the anti-collision manoeuvre in order to minimize the risk of collision, which in practice is achieved by satisfying the following inequality:

$$
\left[\mathrm{S}_{\mathrm{o}}^{(\varepsilon)}, \mathrm{S}_{\mathrm{j}}^{(\varepsilon)}\right]
$$

$D_{\min }^{\mathrm{j}} \quad-$ the smallest distance of approach of the own ship and the $\mathrm{j}$-th encountered object,

$\mathrm{D}_{\mathrm{s}} \quad-\quad$ safe approach distance in the prevailing conditions depends on the visibility conditions at sea, the COLREG Rules and the ship's dynamics.

$\mathrm{D}_{\mathrm{j}} \quad-\quad$ current distance to the $\mathrm{j}$-th object taken from the ARPA anti-collision system.

$\varepsilon=-1-$ refers to the manoeuvring of the ship in order to achieve the closest point of approach, for example during the approach of a rescue vessel, transfer of cargo from ship to ship, destruction the enemy's ship, etc.).

In the adopted describing symbols we can discriminate the following type of steering ship in order to achieve a determined goal:
- basic type of steering, stabilization of the course or trajectory: $\left[\mathrm{S}_{\mathrm{o}}^{(0)}, \mathrm{S}_{\mathrm{j}}^{(0)}\right]$

- avoidance of a collision by executing:

a) own ship's manoeuvres: $\left[\mathrm{S}_{\mathrm{o}}^{(1)}, \mathrm{S}_{\mathrm{j}}^{(0)}\right]$

b) manoeuvres of the $\mathrm{j}$-th ship: $\left[\mathrm{S}_{\mathrm{o}}^{(0)}, \mathrm{S}_{\mathrm{j}}^{(1)}\right]$

c) co-operative manoeuvres: $\left[\mathrm{S}_{\mathrm{o}}^{(1)}, \mathrm{S}_{\mathrm{j}}^{(1)}\right]$

- encounter of the ships: $\left[\mathrm{S}_{\mathrm{o}}^{(-1)}, \mathrm{S}_{\mathrm{j}}^{(-1)}\right]$

situations of a unilateral dynamic game: $\left[\mathrm{S}_{\mathrm{o}}^{(-1)}, \mathrm{S}_{\mathrm{j}}^{(0)}\right]$ and $\left[\mathrm{S}_{\mathrm{o}}^{(0)}, \mathrm{S}_{\mathrm{j}}^{(-1)}\right]$

Dangerous situations resulting from a faulty assessment of the approaching process by one of the party with the other party's failure to conduct observation - one ship is equipped with a radar or an anti-collision system, the other with a damaged radar or without this device [32].

- chasing situations which refer to a typical conflicting dynamic game: $\left[\mathrm{S}_{\mathrm{o}}^{(-1)}, \mathrm{S}_{\mathrm{j}}^{(1)}\right]$ and $\left[\mathrm{S}_{\mathrm{o}}^{(1)}, \mathrm{S}_{\mathrm{j}}^{(-1)}\right]$.

The first case usually represents regular optimal control, the second and third are unilateral games while the fourth and fifth cases represent the conflicting games.

\section{BASE MATHEMATICAL MODEL OF GAME SHIP CONTROL}

As the process of steering the ship in collision situations, when a greater number of objects is encountered, often occurs under the conditions of indefiniteness and conflict, accompanied by an inaccurate co-operation of the ships within the context of COLREG Regulations then the most adequate model of the process which has been adopted is a model of a dynamic game, in general of $\mathrm{j}$ tracked ships as objects of steering.

The diversity of selection of possible models directly affects the synthesis of the ship's handling algorithms which are afterwards effected by the ship's handling device directly linked to the ARPA system and, consequently, determines the effects of the safe and optimal control.

The most general description of the own ship passing the $\mathrm{j}$ number of other encountered ships is the model of a differential game of a j number of objects, shown in Fig. 5.

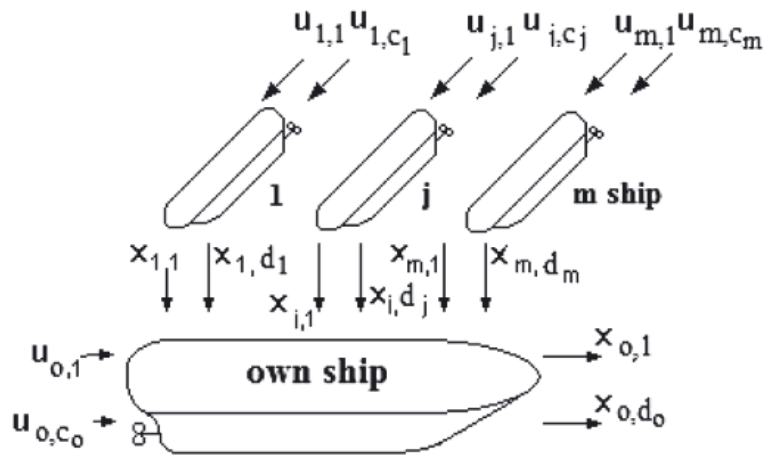

Fig. 5. Block diagram of a base dynamic game model

The properties of the process are described by the state equation:

$$
\mathrm{i}=1, \ldots,\left(\mathrm{jd}_{\mathrm{j}}+\mathrm{d}_{\mathrm{o}}\right) ; \mathrm{j}=1, \ldots, \mathrm{m}
$$

where:

$\vec{x}_{0, d_{o}}(t)-d_{o}$ dimensional vector of the process state of the own ship determined in a time span $\mathrm{t} \in\left[\mathrm{t}_{0}, \mathrm{t}_{\mathrm{k}}\right]$,

$\vec{x}_{j, d_{j}}(t)-d_{j}$ dimensional vector of the process state for the $j$-th ship, 
$\overrightarrow{\mathrm{u}}_{\mathrm{o}, \mathrm{c}_{\mathrm{o}}}(\mathrm{t})-\mathrm{c}_{\mathrm{o}}$ dimensional control vector of the own ship, $\overrightarrow{\mathrm{u}}_{\mathrm{j}, \mathrm{c}_{\mathrm{j}}}(\mathrm{t})-\mathrm{c}_{\mathrm{j}}$ dimensional control vector of the $\mathrm{j}$-th ship.

Taking into consideration the equations reflecting the own ship's hydromechanics and equations of the own ship's movement relative to the $\mathrm{j}$-th encountered ship, the equations of the general state of the process (7) take the form (8).

$$
\begin{aligned}
& \dot{\mathrm{x}}_{\mathrm{o}, 1}=\mathrm{x}_{\mathrm{o}, 2} \\
& \dot{x}_{\mathrm{o}, 2}=\mathrm{a}_{1} \mathrm{x}_{\mathrm{o}, 2} \mathrm{x}_{\mathrm{o}, 3}+\mathrm{a}_{2} \mathrm{x}_{\mathrm{o}, 3}\left|\mathrm{x}_{\mathrm{o}, 3}\right|+\mathrm{b}_{1} \mathrm{x}_{\mathrm{o}, 3}\left|\mathrm{x}_{\mathrm{o}, 3}\right| \mathrm{u}_{\mathrm{o}, 1} \\
& \dot{x}_{0,3}=a_{4} x_{0,3}\left|x_{0,3} \| x_{0,4}\right| x_{0,4}\left(1+x_{0,4}\right)+ \\
& +a_{5} x_{0,2} x_{0,3} x_{0,4}\left|x_{0,4}\right|+a_{6} x_{0,2} x_{0,3} x_{0,4}+a_{7} x_{0,3}\left|x_{0,3}\right|+ \\
& +a_{8} x_{0,5}\left|x_{0,5}\right| x_{0,6}+b_{2} x_{0,3} x_{0,4}\left|x_{0,3} u_{0,1}\right| \\
& \dot{x}_{0,4}=a_{3} x_{0,3} x_{0,4}+a_{4} x_{0,3} x_{0,4}\left|x_{0,4}\right|+a_{5} x_{0,2} x_{0,2}+ \\
& +\mathrm{a}_{9} \mathrm{x}_{\mathrm{o}, 2}+\mathrm{b}_{2} \mathrm{x}_{\mathrm{o}, 3} \mathrm{u}_{\mathrm{o}, 1} \\
& \dot{\mathrm{x}}_{\mathrm{o}, 5}=\mathrm{a}_{10} \mathrm{x}_{\mathrm{o}, 5}+\mathrm{b}_{3} \mathrm{u}_{\mathrm{o}, 2} \\
& \dot{\mathrm{x}}_{\mathrm{o}, 6}=\mathrm{a}_{11} \mathrm{x}_{\mathrm{o}, 6}+\mathrm{b}_{4} \mathrm{u}_{\mathrm{o}, 3} \\
& \dot{x}_{\mathrm{j}, 1}=-\mathrm{x}_{\mathrm{o}, 3}+\mathrm{x}_{\mathrm{j}, 2} \mathrm{x}_{\mathrm{o}, 2}+\mathrm{x}_{\mathrm{j}, 3} \cos \mathrm{x}_{\mathrm{j}, 3} \\
& \dot{\mathrm{x}}_{\mathrm{j}, 2}=-\mathrm{x}_{\mathrm{o}, 2} \mathrm{x}_{\mathrm{j}, 1}+\mathrm{x}_{\mathrm{j}, 3} \sin \mathrm{x}_{\mathrm{j}, 3} \\
& \dot{x}_{\mathrm{j}, 3}=-\mathrm{x}_{\mathrm{o}, 2}+\mathrm{b}_{4+\mathrm{j}} \mathrm{x}_{\mathrm{j}, 3} \mathrm{u}_{\mathrm{j}, 1} \\
& \dot{x}_{j, 4}=a_{11+j} x_{j, 4}\left|x_{j, 4}\right|+b_{5+j} u_{j, 2}
\end{aligned}
$$

The state variables are represented by the following values:

$\mathrm{x}_{\mathrm{o}, 1}=\psi-$ course of the own ship,

$\mathrm{x}_{0,2}=\dot{\psi}-$ angular turning speed of the own ship,

$\mathrm{x}_{\mathrm{o}, 3}=\mathrm{V}-$ speed of the own ship,

$x_{0,4}=\beta-$ drift angle of the own ship,

$\mathrm{x}_{\mathrm{o}, 5}=\mathrm{n}$ - rotational speed of the screw propeller of the own ship,

$\mathrm{x}_{\mathrm{o}, 6}=\mathrm{H}-$ pitch of the adjustable propeller of the own ship,

$\mathrm{x}_{\mathrm{j}, 1}=\mathrm{D}_{\mathrm{j}}$ - distance to $\mathrm{j}$-th object, or $\mathrm{x}_{\mathrm{j}}$ - its coordinate,

$\mathrm{x}_{\mathrm{j}, 2}=\mathrm{N}_{\mathrm{j}}$ - bearing of the $\mathrm{j}$-th object, or $\mathrm{y}_{\mathrm{j}}$ - its coordinate,

$\mathrm{x}_{\mathrm{j}, 3}=\psi_{\mathrm{j}}$ - course of the $\mathrm{j}$-th object, or $\beta_{\mathrm{j}}$ - relative meeting angle,

$\mathrm{x}_{\mathrm{j}, 4}=\mathrm{V}_{\mathrm{j}}$ - speed of the $\mathrm{j}$-th object,

where: $d_{o}=6, d_{j}=4$.

While the control values are represented by:

$\mathrm{u}_{\mathrm{o}, 1}=\alpha_{\mathrm{r}}-$ reference rudder angle of the own ship, or $\dot{\psi}$ - angular turning speed of the own ship, or $\psi$ - course of the own ship, depending of a kind approximated model of process,

$\mathrm{u}_{\mathrm{o}, 2}=\mathrm{n}_{\mathrm{r}}-$ reference rotational speed of the own ship's screw

\begin{tabular}{|c|c|c|}
\hline Coefficient & Measure & Value \\
\hline$a_{1}$ & $\mathrm{~m}^{-1}$ & $-4.143 \cdot 10^{-2}$ \\
\hline $\mathrm{a}_{2}$ & $\mathrm{~m}^{-2}$ & $1.858 \cdot 10^{-4}$ \\
\hline$a_{3}$ & $\mathrm{~m}^{-1}$ & $-6.934 \cdot 10^{-3}$ \\
\hline$a_{4}$ & $\mathrm{~m}^{-1}$ & $-3.177 \cdot 10^{-2}$ \\
\hline$a_{5}$ & - & -4.435 \\
\hline$a_{6}$ & - & -0.895 \\
\hline$a_{7}$ & $\mathrm{~m}^{-1}$ & $-9.284 \cdot 10^{-4}$ \\
\hline$a_{8}$ & - & $1.357 \cdot 10^{-3}$ \\
\hline$a_{9}$ & - & 0.624 \\
\hline$a_{10}$ & $\mathrm{~s}^{-1}$ & -0.200 \\
\hline$a_{11}$ & $\mathrm{~s}^{-1}$ & -0.100 \\
\hline$a_{11+j}$ & $\mathrm{~s} \cdot \mathrm{m}^{-1}$ & $-7.979 \cdot 10^{-4}$ \\
\hline $\mathrm{b}_{1}$ & $\mathrm{~m}^{-2}$ & $1.134 \cdot 10^{-2}$ \\
\hline $\mathrm{b}_{2}$ & $\mathrm{~m}^{-1}$ & $-1.554 \cdot 10^{-3}$ \\
\hline $\mathrm{b}_{3}$ & $\mathrm{~s}^{-1}$ & 0.200 \\
\hline $\mathrm{b}_{4}$ & $\mathrm{~s}^{-1}$ & 0.100 \\
\hline$b_{4+j}$ & $\mathrm{~m}^{-1}$ & $-3.333 \cdot 10^{-3}$ \\
\hline$b_{5+j}$ & $\mathrm{~m} \cdot \mathrm{s}^{-1}$ & $9.536 \cdot 10^{-2}$ \\
\hline
\end{tabular}
propeller, or force of the propeller thrust of the own ship, or speed of the own ship,

$\mathrm{u}_{\mathrm{o}, 3}=\mathrm{H}_{\mathrm{r}}-$ reference pitch of the adjustable propeller of the own ship,

$\mathrm{u}_{\mathrm{j}, 1}=\psi_{\mathrm{j}}$ - course of the $\mathrm{j}$-th object, or $\dot{\psi}_{\mathrm{j}}$ - angular turning speed of the j-th object,

$\mathrm{u}_{\mathrm{j}, 2}=\mathrm{V}_{\mathrm{j}}$ - speed of the $\mathrm{j}$-th object, or force of the propeller thrust of the j-th object,

where: $c_{o}=3, c_{j}=2$.
Values of coefficients of the process state equations (8) for the 12000 DWT container ship are given in Table 1.

Tab. 1. Coefficients of basic game model equations.

In example for $\mathrm{j}=20$ objects the base game model is represented by $i=86$ state variables of process control.

The constraints of the control and the state of the process are connected with the basic condition for the safe passing of the objects at a safe distance $\mathrm{D}_{\mathrm{s}}$ in compliance with COLREG Rules, generally in the following form:

$$
\mathrm{g}_{\mathrm{j}}\left(\mathrm{x}_{\mathrm{j}, \mathrm{d}_{\mathrm{j}}}, \mathrm{u}_{\mathrm{j}, \mathrm{c}_{\mathrm{j}}}\right) \leq 0
$$

The constraints referred to as the ships domains in the marine navigation, may assume a shape of a circle, ellipse, hexagon, or parabola and may be generated for example by an artificial neural network as is shown in Fig. $6[33,34]$.

The synthesis of the decision making pattern of the object control leads to the determination of the optimal strategies of the players who determine the most favourable, under given conditions, conduct of the process. For the class of noncoalition games, often used in the control techniques, the most beneficial conduct of the own control object as a player with $\mathrm{j}$-th object is the minimization of her goal function in the form of the payments - the integral payment and the final one:

$$
I_{\mathrm{o}, \mathrm{j}}=\int_{\mathrm{t}_{0}}^{\mathrm{t}_{\mathrm{k}}}\left[\mathrm{x}_{\mathrm{o}, \mathrm{d}_{\mathrm{o}}}(\mathrm{t})\right]^{2} \mathrm{dt}+\mathrm{r}_{\mathrm{j}}\left(\mathrm{t}_{\mathrm{k}}\right)+\mathrm{d}\left(\mathrm{t}_{\mathrm{k}}\right) \rightarrow \min
$$

The integral payment represents loss of way by the ship while passing the encountered objects and the final payment determines the final risk of collision $r_{j}\left(t_{k}\right)$ relative to the $j$ th object and the final deflection of the ship $d\left(t_{k}\right)$ from the reference trajectory.

Generally two types of the steering goals are taken into consideration - programmed steering $\mathrm{u}_{\mathrm{o}}(\mathrm{t})$ and positional steering $\mathrm{u}_{\mathrm{o}}\left[\mathrm{x}_{\mathrm{o}}(\mathrm{t})\right]$. The basis for the decision making steering 
are the decision making patterns of the positional steering processes, the patterns with the feedback arrangement representing the dynamic games.

The application of reductions in the description of the own ship's dynamics and the dynamic of the j-th encountered ship and their movement kinematics lead to synthesis of game ship control algorithms in collisions situations.

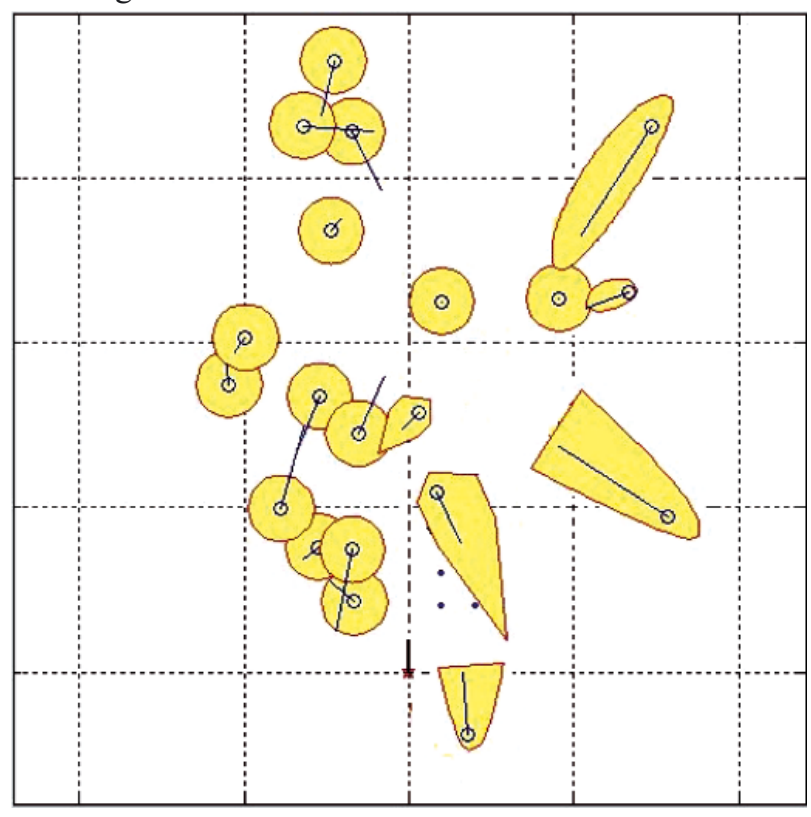

Fig. 6. The shapes of the neural domains in the situation of 20 encountered ships in Kattegat Strait

\section{ALGORITHMS OF GAME SHIP CONTROL}

\section{Multi-stage positional game control algorithms}

The general model of dynamic game is simplified to the multi-stage positional game of $\mathrm{j}$ participants not co-operating among them $[35,36]$.

State variables and control values are represented by:

$$
\left.\begin{array}{r}
\mathrm{x}_{\mathrm{o}, 1}=\mathrm{X}_{0}, \mathrm{x}_{\mathrm{o}, 2}=\mathrm{Y}_{0}, \mathrm{x}_{\mathrm{j}, 1}=\mathrm{X}_{\mathrm{j}}, \mathrm{x}_{\mathrm{j}, 2}=\mathrm{Y}_{\mathrm{j}} \\
\mathrm{u}_{\mathrm{o}, 1}=\psi, \mathrm{u}_{\mathrm{o}, 2}=\mathrm{V}, \mathrm{u}_{\mathrm{j}, 1}=\psi_{\mathrm{j}}, \mathrm{u}_{\mathrm{j}, 2}=\mathrm{V}_{\mathrm{j}} \\
\mathrm{j}=1,2, \ldots, \mathrm{m}
\end{array}\right\}
$$

The essence of the positional game is to subordinate the strategies of the own ship to the current positions $\mathrm{p}\left(\mathrm{t}_{\mathrm{k}}\right)$ of the encountered objects at the current step $\mathrm{k}$. In this way the process model takes into consideration any possible alterations of the course and speed of the encountered objects while steering is in progress. The current state of the process is determined by the co-ordinates of the own ship's position and the positions of the encountered objects:

$$
x_{o}=\left(X_{0}, Y_{0}\right) ; x_{j}=\left(X_{j}, Y_{j}\right) j=1,2, \ldots, m
$$

The system generates its steering at the moment $t_{k}$ on the basis of data received from the ARPA anti-collision system pertaining to the positions of the encountered objects:

$p\left(t_{k}\right)=\left[\begin{array}{l}x_{o}\left(t_{k}\right) \\ x_{j}\left(t_{k}\right)\end{array}\right] j=1,2, \ldots, m ; k=1,2, \ldots, K$

It is assumed, according to the general concept of a multistage positional game, that at each discrete moment of time $t_{k}$ the own ship knows the positions of the objects.
The constraints for the state co-ordinates:

$$
\left\{\mathrm{x}_{\mathrm{o}}(\mathrm{t}), \mathrm{x}_{\mathrm{j}}(\mathrm{t})\right\} \in \mathrm{P}
$$

are navigational constraints, while steering constraints:

$$
\mathrm{u}_{\mathrm{o}} \in \mathrm{S}_{\mathrm{o}}, \mathrm{u}_{\mathrm{j}} \in \mathrm{S}_{\mathrm{j}} \mathrm{j}=1,2, \ldots, \mathrm{m}
$$

take into consideration: the ships' movement kinematics, recommendations of the COLREG Rules and the condition to maintain a safe passing distance as per relationship (6).

The closed sets $S_{o, j}$ and $S_{o, j}$, defined as the sets of acceptable strategies of the participants to the game towards one another:

$$
\left\{\mathrm{S}_{\mathrm{o}, \mathrm{j}}[\mathrm{p}(\mathrm{t})], \mathrm{S}_{\mathrm{j}, \mathrm{o}}[\mathrm{p}(\mathrm{t})]\right\}
$$

are dependent, which means that the choice of steering $u_{j}$ by the $j$-th object changes the sets of acceptable strategies of other ships.

\section{Multi-stage non-cooperative positional game control algorithm mspg_nc.12}

The optimal steering of the own $\operatorname{ship} \mathrm{u}_{\mathrm{o}}^{*}(\mathrm{t})$, equivalented for the current position $\mathrm{p}(\mathrm{t})$ to the optimal positional control $\mathrm{u}_{\mathrm{o}}^{*}(\mathrm{p})$. The sets of acceptable strategies $U_{i, o}\left[p\left(t_{k}\right)\right]$ are determined for the encountered ships relative to the own ship and initial sets $\mathrm{U}_{\mathrm{o}, \mathrm{L}}\left[\mathrm{p}\left(\mathrm{t}_{\mathrm{k}}\right)\right]$ of acceptable strategies of the own ship relative to each one of the encountered ship. The pair of vectors $u_{j}$ and $u_{o, j}$ relative to each $\mathrm{j}$-th ship is determined and then the optimal positional strategy for the own ship $u_{0}^{*}(p)$ from the condition (10).

$$
I_{\mathrm{o}}^{*}=\min _{\mathrm{u}_{\mathrm{o}} \in \bigcap_{\mathrm{j}=1}^{m} \mathrm{~S}_{\mathrm{o}, \mathrm{j}}} \max _{\mathrm{u}_{\mathrm{j}} \in \mathrm{S}_{\mathrm{j}}} \min _{\mathrm{o}, \mathrm{j}} \int_{\mathrm{o}, \mathrm{j}}^{\mathrm{t}_{0}} \mathrm{u}_{\mathrm{o}}(\mathrm{t}) \mathrm{dt}=\mathrm{S}_{\mathrm{o}}^{*}\left(\mathrm{x}_{\mathrm{O}}, \mathrm{L}_{\mathrm{k}}\right)
$$

The function $\mathrm{S}_{\mathrm{o}}$ refers to the continuous function of the manoeuvring goal of the own ship, characterising the distance of the ship at the initial moment $t_{0}$ to the nearest turning point $\mathrm{L}_{\mathrm{k}}$ on the reference $\mathrm{p}_{\mathrm{r}}\left(\mathrm{t}_{\mathrm{k}}\right)$ route of the voyage.

The optimal control of the own ship is calculated at each discrete stage of the ship's movement by applying the Simplex method to solve the problem of the triple linear programming, assuming the relationship (17) as the goal function and the control constraints (9).

\section{Multi-stage cooperative positional game control algorithm mspg_c.12}

The quality index of control for a cooperative game has the form:

$$
I_{\mathrm{O}}^{*}=\min _{\mathrm{u}_{\mathrm{o}} \in \bigcap_{\mathrm{m}=1}^{m} \mathrm{~S}_{\mathrm{o}, \mathrm{j}}} \min _{\mathrm{u}_{\mathrm{j}} \in \mathrm{S}_{\mathrm{j}}} \min _{\mathrm{o}, \mathrm{j}} \in \mathrm{S}_{\mathrm{o}, \mathrm{j}} \int_{\mathrm{t}_{0}}^{\mathrm{t}_{\mathrm{k}}} \mathrm{u}_{\mathrm{o}}(\mathrm{t}) \mathrm{dt}=\mathrm{S}_{\mathrm{o}}^{*}\left(\mathrm{x}_{\mathrm{O}}, \mathrm{L}_{\mathrm{k}}\right)
$$$$
\text { Multi-step matrix game control algorithms }
$$

When leaving aside the ship's dynamics equations the general model of a dynamic game for the process of preventing collisions is reduced to the matrix game of $\mathrm{j}$ participants nonco-operating among them [9].

The state and steering variables are represented by the following values:

$$
\begin{gathered}
\mathrm{x}_{\mathrm{j}, 1}=\mathrm{D}_{\mathrm{j}}, \mathrm{x}_{\mathrm{j}, 2}=\mathrm{N}_{\mathrm{j}}, \mathrm{u}_{\mathrm{o}, 1}=\psi, \mathrm{u}_{\mathrm{o}, 2}=\mathrm{V}, \mathrm{u}_{\mathrm{j}, 1}=\psi_{\mathrm{j}}, \mathrm{u}_{\mathrm{j}, 2}=\mathrm{V}_{\mathrm{j}} \\
\mathrm{j}=1,2, \ldots, \mathrm{m}
\end{gathered}
$$


The game matrix $R=\left[r_{j}\left(u_{j}, u_{o}\right)\right]$ includes the values of the collision risk $r_{j}$ determined from relation (1) on the basis of data obtained from the ARPA anti-collision system for the acceptable strategies $u_{o}$ of the own ship and acceptable strategies $u_{j}$ of any particular number of $\mathrm{j}$ encountered objects.

The problem of determining an optimal strategy may be reduced to the task of solving dual linear programming Simplex method. Mixed strategy components express the distribution of probability $p_{j}\left(u_{o}, u_{j}\right)$ of using pure strategies by the players $[20,21]$.

\section{Multi-step non-cooperative matrix game control algorithm msmg_nc.12}

As a result of using the following form for the control goal:

$$
I_{o}^{*}=\min _{u_{o}} \max _{u_{j}} r_{j}
$$

the probability matrix $\mathbf{P}=\left[\mathrm{p}_{\mathrm{j}}\left(\mathrm{u}_{\mathrm{o}}, \mathrm{u}_{\mathrm{j}}\right)\right]$ of using particular pure strategies may be obtained.

The solution for the control problem is the strategy representing the highest probability:

$$
\mathrm{u}_{\mathrm{o}}^{*}=\mathrm{u}_{\mathrm{o}}\left\{\left[\mathrm{p}_{\mathrm{j}}\left(\mathrm{u}_{\mathrm{o}}, \mathrm{u}_{\mathrm{j}}\right)\right]_{\max }\right\}
$$

\section{Multi-step cooperative matrix game control algorithm msmg_c.12}

The quality index of control for a cooperative game has the form:

$$
I_{o}^{*}=\min _{u_{0}} \min _{u_{j}} r_{j}
$$

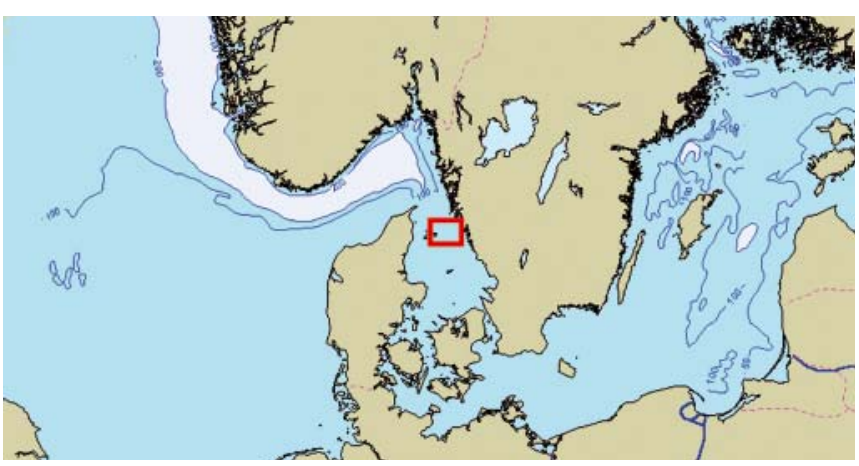

Fig. 7. The place of identification of navigational situation in Kattegat Strait

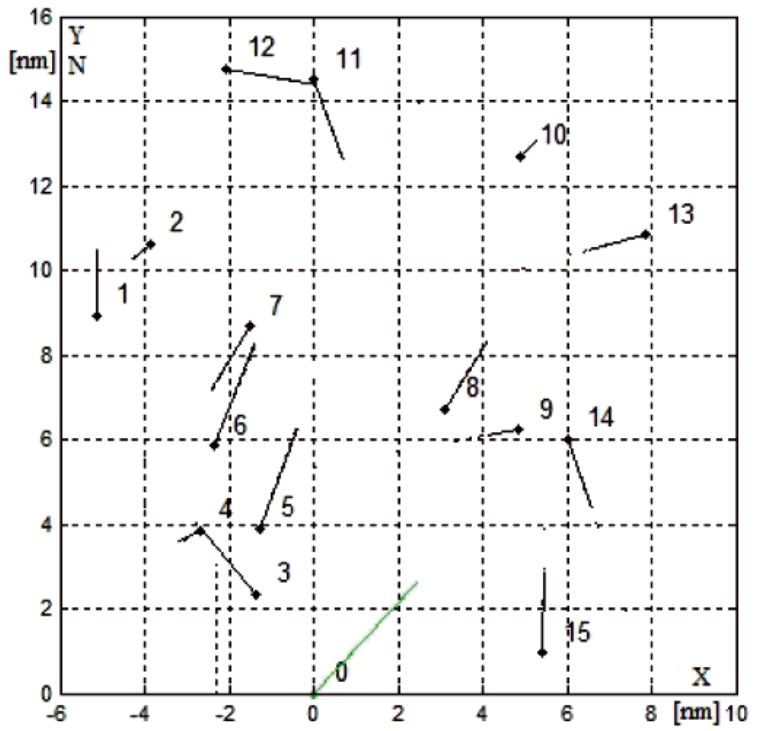

Fig. 8. The 12 minute speed vectors of own ship and 15 encountered ships in navigational situation in Kattegat Strait

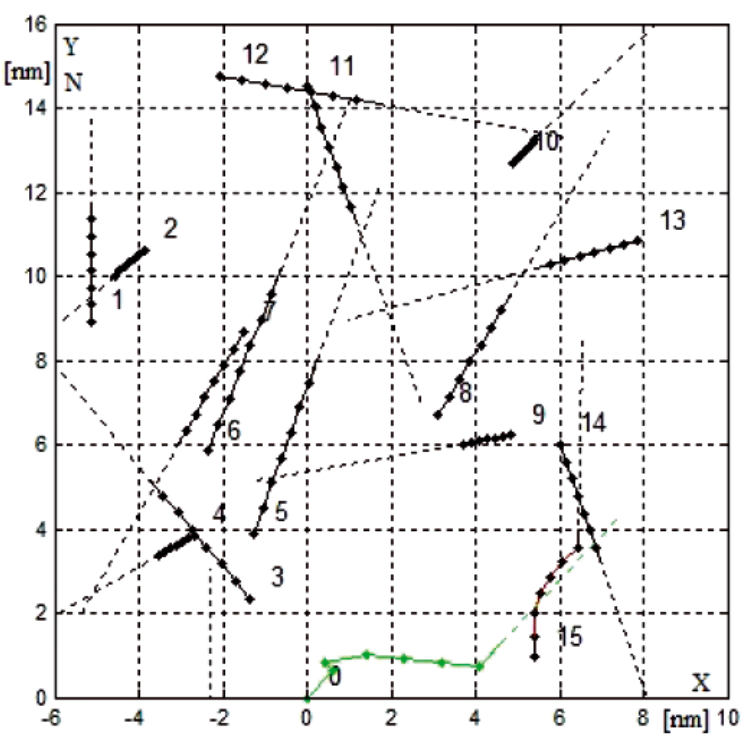

Fig. 9. Computer simulation of $\mathbf{m s p g} \boldsymbol{n c . 1 2}$ algorithm for safe manoeuvring of the own ship in situation of passing 15 encountered ships, $D_{s}=1.0 \mathrm{~nm}$, $d\left(t_{k}\right)=2.49 \mathrm{~nm}$ (nautical mile)

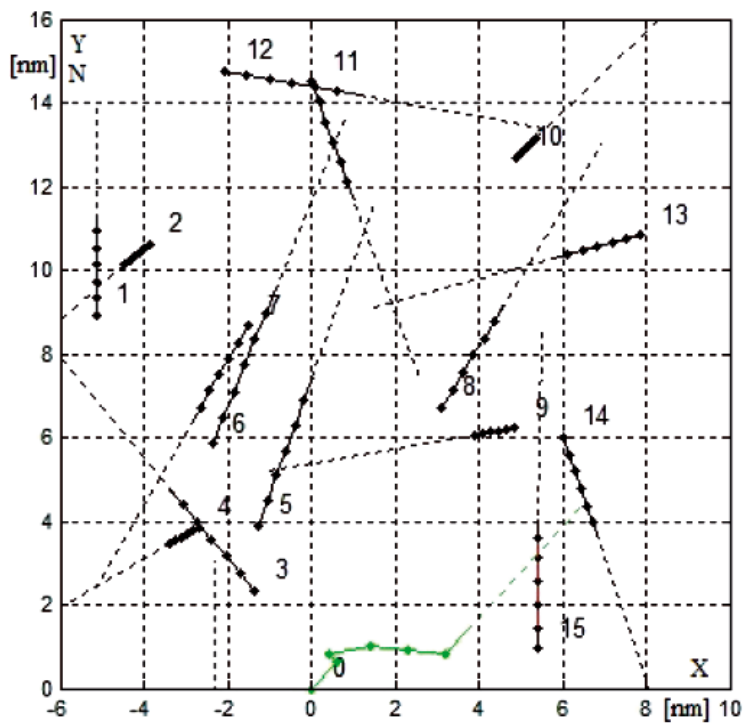

Fig. 10. Computer simulation of mspg_c.12 algorithm for safe manoeuvring of the own ship in situation of passing 15 encountered ships, $D_{s}=1.0 \mathrm{~nm}$, $d\left(t_{k}\right)=1.78 \mathrm{~nm}$

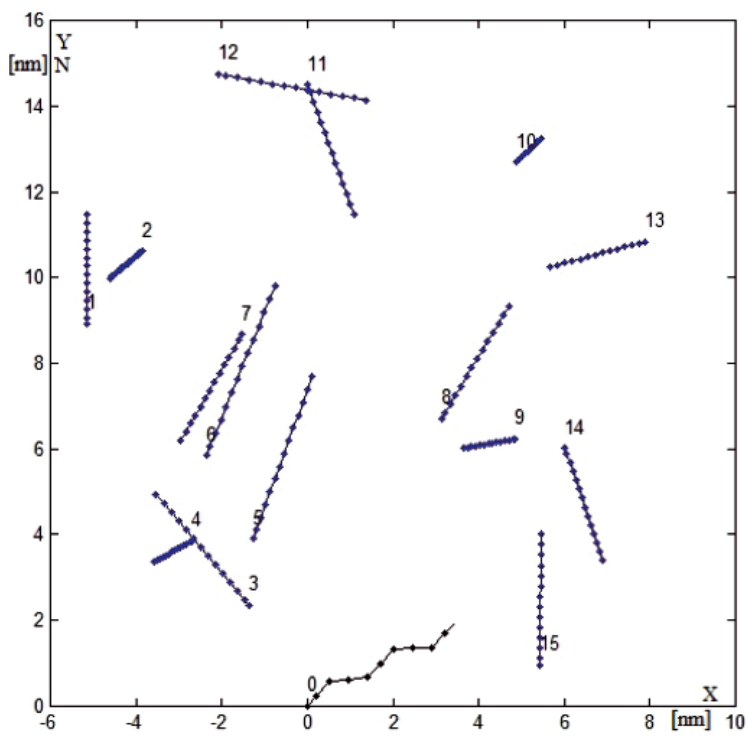

Fig. 11. Computer simulation of msmg nc.12 algorithm for safe manoeuvring of the own ship in situation of passing 15 encountered ships, $D_{s}=1.0 \mathrm{~nm}, d\left(t_{k}\right)=1.86 \mathrm{~nm}$ 


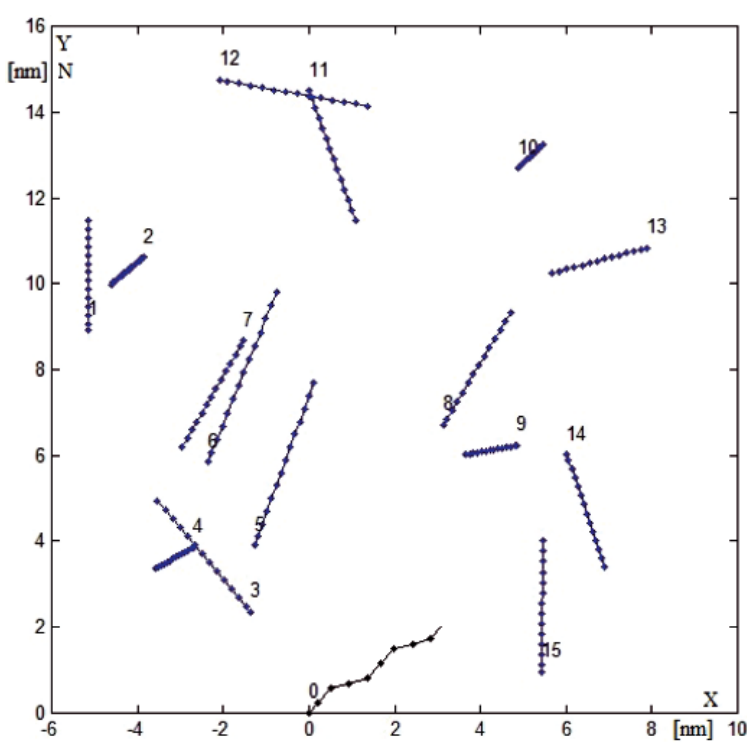

Fig. 12. Computer simulation of $\mathbf{m s m g}$ c.12 algorithm for safe manoeuvring of the own ship in situation of passing 15 encountered ships, $D_{s}=1.0 \mathrm{~nm}, d\left(t_{k}\right)=1.24 \mathrm{~nm}$

\section{COMPUTER SIMULATION}

Computer simulation of control game algorithms were carried out on an example of a real navigational situations of passing $\mathrm{j}=15$ encountered ships. The situations were registered in Kattegat Strait on board r/v HORYZONT II, a research and training vessel of the Gdynia Maritime University, on the radar screen of the ARPA anti-collision system Raytheon (Fig. 7 and 8).

Examples of safe positional game trajectories are shown in Fig. 9 and 10.

Examples of safe matrix game trajectories are shown in Fig. 11 and 12.

\section{CONCLUSIONS}

- The application of the models of a game theory for the synthesis of an optimal manoeuvring makes it possible to determine the safe game trajectory of the own ship in situations when she passes a greater number of the encountered ships.

- Developed algorithms takes also into consideration the Rules of the COLREGS Rules and the advance time of the manoeuvre approximating ship's dynamic properties and evaluates the final deviation of the real trajectory from reference value.

- The positional game control algorithms determine game and safe trajectory of the own ship with relation to of all encountered ships.

- The matrix game control algorithms determine game and safe trajectory of the own ship with relation to of the ship of most dangerous.

- To sum up it may be stated that the control methods considered in this study are, in a certain sense, formal models for the thinking processes of a navigating officer steering of own ship and making decisions on manoeuvres.

- Therefore they may be applied in the construction of a new model of ARPA system containing a computer supporting the navigator's decision making.

\section{BIBLIOGRAPHY}

1. Lisowski J.: Computational intelligence methods in the safe ship control process. Polish Maritime Research. No 1,Vol. 8, 2001, p. 18-24.

2. Nise N.S.: Control systems engineering. John Wiley and Sons, New York, 2011.

3. Bole A., Dineley B., Wall A.: Radar and ARPA manual. Elsevier, Amsterdam-Tokyo, 2006.

4. Cahill R.A.: Collisions and their causes. The Nautical Institute, London, 2002.

5. Gluver H., Olsen D.: Ship collision analysis. Balkema, Rotterdam, 1998.

6. Cockcroft A.N., Lameijer N.F.: Collision avoidance rules. Elsevier, Amsterdam-Tokyo, 2006.

7. Bist D.S.: Safety and security at sea. Butterworth Heinemann, Oxford-New Delhi, 2000.

8. Modarres M.: Risk analysis in engineering. Taylor and Francis Group, Boca Raton, 2006.

9. Lisowski J.: Multi-step matrix game with the risk of ship collision. In C.A. Brebbia (Ed), Risk Analysis IV: Simulation and Hazard Mitigation, WIT Press Computational Mechanics Inc., Southampton-Boston, 2004, p. 669-680.

10.Lisowski J.: Mathematical modeling of a safe ship optimal control process. Polish Journal of Environmental Studies, Vol. 14, 2005, p. 68-75.

11.Zio E.: Computational methods for reliability and risk analysis. Quality, Reliability and Engineering Statistics, No 14, Word Scientific, New Jersey-Chennai, 2009, p. 295-334.

12.Lisowski J.: Game control methods in navigator decision support system. The Archives of Transport, No 3-4, Vol. XVII, 2005, p. 133-147.

13.Lisowski J.: Computer support of navigator manoeuvring decision in congested waters. Polish Journal of Environmental Studies, Vol. 17, No 5A, 2008, p. 1-9.

14.Lisowski J.: Optimization decision support system for safe ship control. In C.A. Brebbia (Ed), Risk Analysis VII: Simulation and Hazard Mitigation, WIT Press Computational Mechanics Inc., Southampton-Boston, 2010, p. 259-272.

15.Łebkowski A.: Hybrydowy system sterowania obiektem ruchomym w środowisku dynamicznym. Doctoral thesis, Gdańsk Technology University, Gdańsk, 2006.

16.Pietrzykowski Z.: The navigational decision support system on a sea-going vessel. Maritime University, Szczecin, 2011.

17.Szłapczynski R., Śmierzchalski R.: Supporting navigators decisions by visualizing ship collision risk. Polish Maritime Research, Vol. 59, No 1, 2009, p. 83-88.

18.Lisowski J.: Comparative analysis of safe ship control methods. Proc. of $11^{\text {th }}$ Int. Conf. on Methods and Models in Automation and Robotics, Międzyzdroje, 2005, p. 149-154.

19.Lisowski J., Mohamed-Seghir M.: Safe ship control methods based on fuzzy set theory. Polish Journal of Environmental Studies, Vol. 17, No 3C, 2008, p. 55-58.

20.Lisowski J., Pachciarek A.: Transmisja danych nawigacyjnych w uktadzie komputerowego wspomagania decyzji manewrowej nawigatora w sytuacji kolizyjnej. Przegląd Telekomunikacyjny, nr 1, 2009, s. 33-35.

21.Lisowski J.: Safety of navigation based on game theory mathematical models of game ship control. Journal of Shanghai Maritime University, Vol. 25, No 104, 2004, p. 65-74.

22.Lisowski J.: The dynamic game theory methods applied to ship control with minimum risk of collision. In C.A. Brebbia (Ed), Risk Analysis V: Simulation and Hazard Mitigation, WIT Press Computational Mechanics Inc., Southampton-Boston, 2006, p. 293-302.

23.Lisowski J.: Game and optimal safe ship control. Chapter in monograph: Recent advances in control and automation, Exit, Warszawa, 2008, p. 302-312.

24.Isaacs R.: Differential games. John Wiley and Sons, New York, 1965. 
25.Baba N. and Jain L.C.: Computational intelligence in games. Physica-Verlag, New York, 2001.

26.Millington I. and Funge J.: Artificial intelligence for games. Elsevier, Amsterdam-Tokyo, 2009.

27.Nisan N., Roughgarden T., Tardos E., Vazirani V.V.: Algorithmic game theory. Cambridge University Press, New York, 2007, p. 717-733.

28. Osborne M.J.: An introduction to game theory. Oxford University Press, New York, 2004.

29.Straffin P.D.: Game theory and strategy. Scholar, Warszawa, 2001 (in polish).

30.Engwerda J.C.: LQ dynamic optimization and differential games. John Wiley and Sons, West Sussex, 2005.

31.Lisowski J.: Optimal and game ship control algorithms for avoiding collisions at sea. In C.A. Brebbia (Ed), Risk Analysis VI: Simulation and Hazard Mitigation, WIT Press Computational Mechanics Inc., Southampton-Boston, 2008, p. 525-534.

32.Lisowski J.: Sensitivity of safe game ship control on base information from ARPA radar. Chapter in monograph: Radar Technology, In-Teh, Croatia, 2009, p. 61-86.
33.Lisowski J.: Dynamic programming of safe ship trajectory with neural state constraints. Polish Journal of Environmental Studies, Vol. 18, No 4B, 2009, p. 126-129.

34.Lisowski J.: The optimal and safe trajectories for different forms of neural state constraints. Solid State Phenomena, Trans Tech Publications, Switzerland, Vol. 180, 2012, p. 64-69.

35.Lisowski J.: Optimization of safe ship control using Matlab/ Simulink. Polish Journal of Environmental Studies, Vol. 19, No 4A, 2010, p. 73-76.

36.Lisowski J.: The multistage positional game of marine objects with different degree of cooperation. Solid State Phenomena. Vol. 180, Trans Tech Publications, Switzerland, 2012, p. 56-63.

\section{CONTACT WITH THE AUTHOR}

Józef Lisowski, Prof. Faculty of Marine Electrical Engineering, Gdynia Maritime University, Morska 81-87 81-225 Gdynia, POLAND e-mail: jlis@am.gdynia.pl 